\title{
Qualidade protéica de linhagens de soja com ausência do Inibidor de Tripsina Kunitz e das isoenzimas Lipoxigenases
}

\section{Protein quality of soy lines lacking Kunitz's Trypsin Inhibitor and Lipoxygenase isozymes}

Márcia Regina Pereira MONTEIRO ${ }^{1}$

Neuza Maria Brunoro COSTA²

Maria Goreti de Almeida OLIVEIRA ${ }^{3}$

Christiano Vieira PIRES 4

Maurílio Alves MOREIRA ${ }^{3}$

\section{R E S U M O}

\section{Objetivo}

Avaliar a qualidade protéica de farinhas de soja, que diferem entre si com relação à presença de lipoxigenases e/ou Inibidor de Tripsina Kunitz.

\section{Métodos}

Procedeu-se aos ensaios biológicos com ratos, em que foram avaliados a Razão da Eficiência Protéica, Razão Protéica Líquida, Utilização Protéica Líquida e a digestibilidade. Determinou-se a composição aminoacídica das farinhas e cálculo do Escore Químico Corrigido pela Digestibilidade.

\section{Resultados}

Os valores de Razão da Eficiência Protéica, Razão Protéica Líquida, Utilização Protéica Líquida para as variedades de soja foram inferiores aos valores obtidos para caseína. Para as farinhas sem Inibidor de Tripsina Kunitz foram obtidos valores de digestibilidade maiores que para as farinhas com Inibidor de Tripsina Kunitz, e esses foram bem próximos aos da caseína. Com relação ao teor aminoacídico, constatou-se que o aminoácido limitante dessa soja é lisina e não metionina, ao contrário do que aponta a literatura.

\footnotetext{
${ }^{1}$ Curso de Nutrição, Escola de Enfermagem, Departamento de Enfermagem Aplicada, Universidade Federal de Minas Gerais. Av. Prof. Alfredo Balena, 190, $6^{\circ}$ andar, Santa Efigênia, 30130-100, Belo Horizonte, MG, Brasil. Correspondência para/Correspondence to: M.R.P. MONTEIRO.E-mail: mregina@enf.ufmg.br

2 Departamento de Nutrição e Saúde, Universidade Federal de Viçosa.

3 Departamento de Bioquímica e Biologia Molecular, Universidade Federal de Viçosa.

${ }^{4}$ Doutorando em Bioquímica Agrícola, Universidade Federal de Viçosa.
} 


\section{Conclusão}

A eliminação genética do Inibidor de Tripsina Kunitz melhora consideravelmente a digestibilidade da proteína de soja. Os resultados do Escore Químico Corrigido pela Digestibilidade não indicaram diferença entre as farinhas sem Inibidor de Tripsina Kunitz das farinhas derivadas de linhagens com Inibidor de Tripsina Kunitz, como foi observado pelos resultados da digestibilidade in vivo.

Termos de indexação: soja, inibidores de Tripsina, qualidade protéica, inibidor da Tripsina de soja de Kunitz.

\section{A B S T R A C T}

\section{Objective}

The objective of this work was to evaluate the protein quality of soybean flours that differs from each other in relation to the presence of lypoxigenases and/or Kunitz's Trypsin Inhibitor.

\section{Methods}

Biological assays with rats were carried out to evaluate Protein Efficiency Ratio, Net Protein Ratio, Net Protein Utilization and the digestibility. The determination of the aminoacid composition of the flours and the estimation of Chemical Score Corrected by Digestibility were carried out.

\section{Results}

The Protein Efficiency Ratio, Net Protein Ratio, Net Protein Utilization values for the soybean varieties were inferior to the values obtained for casein. Higher digestibility values were obtained for the flours lacking Kunitz's Trypsin Inhibitor than for the flours with Kunitz's Trypsin Inhibitor present, and those were very close to the values of casein. About the determination the aminoacid composition it was verified that the restraining amino acid of this soybean is lysine, not methionine, differently from what literature indicates.

\section{Conclusions}

The genetic removal of Kunitz's Trypsin Inhibitor improves soybean protein digestibility considerably. Chemical Score Corrected by Digestibility results did not indicate difference between the flours lacking Kunitz's Trypsin Inhibitor and those derived from flours of lines with Kunitz's Trypsin Inhibitor present, as it was observed by the results of in vivo digestibility.

Index terms: soybeans, Trypsin inhibitors, protein quality, Trypsin inhibitor, Kunitz soybean.

\section{N T R O D U Ç Ã O}

A soja tem sido amplamente utilizada como fonte de óleo comestível e proteína para alimentação humana e animal. A existência da soja é descrita desde 1000 anos antes de Cristo no Japão e na China e somente a partir do século XIX esta leguminosa passou a ter importância econômica'.

Os principais constituintes da soja são a proteína e o óleo, sendo que o grão de soja contém cerca de $40 \%$ de proteína e $20 \%$ de óleo em peso seco. É uma boa fonte de minerais e de vitaminas do complexo B. A soja contém ainda, componentes conhecidos como fatores antinutricionais. Estes incluem inibidores de proteases, lectinas, oligossacarídeos, fitatos e saponinas².

A soja tem sido descrita por conter antinutrientes que limitam a sua utilização. Os mais importantes e extensivamente investigados dos antinutrientes protéicos foram os inibidores de proteases. Os inibidores de proteases de soja são constituídos pelo Inibidor de Tripsina Kunitz 
( $\mathrm{KTI})$ e pelo inibidor de tripsina e quimotripsina Bowman-Birk (BBI). Cerca de $80 \%$ da inibição da atividade tríptica de grãos de soja é causada pela ação do KTI. Estes antinutrientes apresentam especificidade de inibir as enzimas proteolíticas e, conseqüentemente, reduzem a digestão protéica de alimentos, proporcionando diminuição no ganho de peso e crescimento dos animais. Desta forma, para aumentar o valor nutricional da soja e seus produtos, há necessidade de processamentos térmicos para inativá-los'

Apesar de a soja possuir bom valor nutritivo, seus produtos sofrem restrições por parte dos consumidores ocidentais, devido ao sabor característico denominado beany flavor. O beany flavor é originado da associação de compostos carbonílicos de cadeia curta com a fração protéica. Estes compostos são produtos finais de uma série de reações que se inicia com a hidroperoxidação de ácidos graxos poliinsaturados, catalisada por lipoxigenases (LOX). Estas enzimas constituem cerca de $1 \%$ do total de proteínas presentes no grão de soja.

O tratamento térmico tem sido usado para melhorar o valor nutricional da soja, porém este tratamento deve ser controlado para evitar a destruição de aminoácidos importantes e a diminuição da biodisponibilidade de outros nutrientes ${ }^{3}$.

Uma forma de resolver o problema dos inibidores e a conseqüência do tratamento térmico elevado sobre a qualidade da proteína seria a eliminação genética desses na soja. O objetivo geral do presente trabalho foi avaliar a digestibilidade e a qualidade protéica de farinhas integrais obtidas de linhagens de soja que diferem com relação à presença do Inibidor de Tripsina Kunitz e/ou lipoxigenases.

\section{MATERIALE MÉTODOS}

Para a seleção do material genético, neste trabalho, foram usados grupos de sementes (bulks) de linhagens de soja (Glycine max (L.) Merrill) na geração RC1F5 (geração F5 do primeiro ciclo de retrocruzamento) do cruzamento entre linhagens derivadas da variedade Itamarati com ausência completa de lipoxigenase (LOX') e linhagens derivadas da variedade Itamarati com ausência completa do Inibidor de Tripsina Kunitz (KTI-). Do cruzamento dessas linhagens foi obtida a geração F1. Em seguida, foram realizados dois ciclos de autofecundação e obtida a geração F3. Sementes F3 foram analisadas para LOX (pela determinação da atividade enzimática) e para KTI (por eletroforese em gel de poliacrilamida) com o objetivo de selecionar os seguintes genótipos: (a) linhagens com ausência completa de LOX e KTI (LOX- KTI'), (b) linhagens com ausência completa de LOX e presença de KTI (LOX- $\left.\mathrm{KTI}^{+}\right)$, (c) linhagens com presença de LOX e ausência de $\mathrm{KTI}\left(\mathrm{LOX}^{+} \mathrm{KTI}\right)$ e (d) linhagens com presença de $\mathrm{LOX}$ e presença de $\mathrm{KTI}\left(\mathrm{LOX}^{+} \mathrm{KTI^{+ }}\right)$. As sementes selecionadas foram novamente multiplicadas, obtendo-se a geração F4. Nas sementes oriundas de plantas F4 foram feitos testes colorimétricos e eletroforese em gel de poliacrilamida com objetivo de confirmar os genótipos das linhagens. Sementes das plantas F4 foram multiplicadas no campo. Portanto, sementes RC1F5 foram utilizadas para a confecção dos bulks.

Para obtenção dos quatro genótipos citados acima foram realizadas análises de atividade enzimática de LOX 1 nas sementes RC1F3 para identificação de sementes homozigotas dominantes e recessivas para LOX1.

Nas sementes homozigotas dominantes e recessivas para LOX1 foram feitas determinação da atividade enzimática para LOX 3. Foram identificadas as sementes homozigotas dominantes e recessivas para LOX 3. Uma vez selecionadas as sementes homozigotas dominantes e recessivas para LOX 1 e 3, o próximo passo foi a análise de $\mathrm{KTI}$ nestas sementes por meio de eletroforese em géis de poliacrilamida. Com este procedimento foram selecionadas sementes de cada um dos quatro genótipos (a) LOX- $\mathrm{KTI}^{-}$, (b) $\mathrm{LOX}^{-} \mathrm{KTI}^{+}$, (c) $\mathrm{LOX}^{+} \mathrm{KTI}^{-}$e (d) $\mathrm{LOX}^{+} \mathrm{KTI}^{+}$. Nas sementes RC1F4 foram realizados testes colorimétricos para LOXe 
análise eletroforética em géis de poliacrilamida para KTI, com o objetivo de confirmar os genótipos previamente selecionados.

A partir de grãos dos quatro genótipos de soja selecionados na geração RC1F5 para LOX e $\mathrm{KTI}$, foram obtidas as farinhas integrais. As sementes selecionadas após serem lavadas sofreram um tratamento térmico de $89^{\circ} \mathrm{C}$ por 5 minutos em calor seco para facilitar a retirada da casca. Após o tratamento térmico, os grãos foram quebrados em moinho de martelo, de forma a resultar em pedaços grandes, promovendo, assim, a separação das cascas secas. Esta separação foi feita usando peneira de abanar para limpar os grãos. As cascas foram descartadas e os grãos em pedaços foram moídos em moinho de martelo, embalados em sacos plásticos e mantidos sob refrigeração.

A determinação dos teores de proteínas, lipídios, cinzas e carboidratos nas farinhas de soja e nas dietas utilizadas no ensaio biológico, foi realizada segundo o método da Association of Official Analytical Chemists ${ }^{4}$.
As farinhas de soja integrais derivadas dos quatro genótipos para presença de LOX e/ou KTI foram utilizadas como fonte de proteína nas dietas experimentais.

A avaliação da qualidade protéica das dietas experimentais foi conduzida por meio de ensaios biológicos, durante 14 dias, utilizando-se 36 ratos machos, raça Wistar, recém-desmamados com 23 dias de idade.

Os animais foram divididos em grupos de seis, de modo que a diferença da média dos pesos entre os grupos não excedesse 10 gramas, conforme recomendação da Association of Official Analytical Chemists ${ }^{4}$, e foram distribuídos em gaiolas individuais, com livre acesso à água e alimento, durante o período experimental.

A composição das dietas foi baseada na dieta AIN-93G5, porém com teor de proteína de $9 \%$ a $10 \%$ (Tabela 1). Após o preparo, determinou-se o teor de proteína de cada dieta, pelo método semimicro Kjeldhal, com amostras em triplicata, usando-se o fator de conversão universal 6,25 para obtenção do teor protéico ${ }^{4}$.

Tabela 1. Composição das dietas experimentais utilizadas no ensaio biológico ( $\mathrm{g} / 100 \mathrm{~g}$ de mistura).

\begin{tabular}{|c|c|c|c|c|c|c|}
\hline \multirow{2}{*}{ Ingredientes } & \multicolumn{6}{|c|}{ Dietas } \\
\hline & Aprotéica & Caseína & D1 & D2 & D3 & D4 \\
\hline Caseína & - & 11,52 & - & - & - & - \\
\hline Farinha de soja & - & - & 22,38 & 24,79 & 22,78 & 24,02 \\
\hline Amido dextrinizado & 13,20 & 13,20 & 13,20 & 13,20 & 13,20 & 13,20 \\
\hline Sacarose & 10,00 & 10,00 & 10,00 & 10,00 & 10,00 & 10,00 \\
\hline Óleo de soja & 7,00 & 7,00 & 7,00 & 7,00 & 7,00 & 7,00 \\
\hline Fibra & 5,00 & 5,00 & 5,00 & 5,00 & 5,00 & 5,00 \\
\hline Mistura mineral & 3,50 & 3,50 & 3,50 & 3,50 & 3,50 & 3,50 \\
\hline Mistura Vitamínica & 1,00 & 1,00 & 1,00 & 1,00 & 1,00 & 1,00 \\
\hline Cloreto de colina & 0,25 & 0,25 & 0,25 & 0,25 & 0,25 & 0,25 \\
\hline L-cistina & 0,30 & 0,30 & 0,30 & 0,30 & 0,30 & 0,30 \\
\hline Amido de milho & 59,75 & 48,23 & 37,37 & 34,96 & 36,97 & 35,73 \\
\hline \% de proteína & $\mathrm{Nd}$ & 9,54 & 9,56 & 9,26 & 9,74 & 9,96 \\
\hline
\end{tabular}

Fonte: Reeves et $a /^{5}$

D1 - dieta de farinha de soja integral sem LOX, sem KTI; D2 - dieta de farinha de soja integral sem LOX, com KTI; D3 - dieta de farinha de soja integral com LOX, sem KTI; D4 - dieta de farinha de soja integral com LOX, com KTI. 
Os animais foram mantidos nas dietas experimentais durante 14 dias. Neste período, determinaram-se digestibilidade verdadeira, PER Operacional (Quociente de Eficiência Protéica), NPR (Razão Protéica Líquida) e NPU (Utilização Protéica Líquida).

Para o cálculo da digestibilidade, as dietas foram marcadas com óxido de cromo a 0,1\% e as fezes coletadas do $7^{\circ}$ ao $14^{\circ}$ dia do experimento, sendo acondicionadas em recipientes individuais e mantidas sob refrigeração. Após o período de coleta, as fezes foram secas em estufa com circulação de ar, a $105^{\circ} \mathrm{C}$ durante 24 horas. Em seguida, foram resfriadas, pesadas e moídas em moinho de navalha para determinação do teor de nitrogênio. Para este fim, foi utilizado o método semimicro Kjeldhal das amostras em triplicatas, segundo a Association of Official Analytical Chemists $^{4}$.

A determinação da digestibilidade verdadeira foi possível pelo emprego de um grupo de seis animais com dieta aprotéica. O cálculo foi feito de acordo com a seguinte fórmula:

$$
D=\frac{I-(F-F K) \times 100}{I} \text { em que: }
$$

$D$ = digestibilidade; $\mid$ = nitrogênio ingerido pelo grupo com dieta-teste; $F$ = nitrogênio fecal do grupo com dieta-teste; e FK = nitrogênio fecal do grupo com dieta aprotéica.

O NPR foi determinado no $14^{\circ}$ dia do experimento, tomando-se o ganho de peso do grupo-teste mais a perda de peso do grupo de dieta aprotéica, em relação ao consumo de proteína do grupo-teste, seguindo o método de Bender \& Doell ${ }^{6}$. Para isto, foi utilizada a seguinte fórmula:

ganho de peso (g) do grupo-teste + perda de NPR = peso $(\mathrm{g})$ do grupo aprotéico

proteína consumida (g) pelo grupo-teste

O PER operacional (utilizando 14 dias de experimento) foi determinado tomando-se o ganho de peso do grupo-teste em relação ao consumo de proteína do grupo-teste. Para isto, foi utilizada a seguinte fórmula:

$$
\text { PER }=\frac{\text { ganho de peso }(\mathrm{g}) \text { do grupo-teste }}{\text { proteína consumida }(\mathrm{g}) \text { pelo grupo-teste }}
$$

Com relação ao NPU, a determinação foi feita pelo método da carcaça, segundo Miller \& Bender ${ }^{7}$ no $14^{\circ}$ dia do experimento.

Os animais foram sacrificados em dessecador, contendo éter etílico. Em seguida, foram abertos e as carcaças colocadas em recipientes de alumínio para secar. Após o período de 24 horas de secagem em estufa a $105^{\circ} \mathrm{C}$, com circulação de ar, as carcaças foram resfriadas, pesadas, trituradas, desengorduradas em extrator Soxhlet, durante 4 a 5 horas com éter de petróleo, e pulverizadas em liquidificador para determinação do teor de nitrogênio, retido nelas. Para isto, foi utilizado o método semimicro Kjeldhal das amostras em triplicatas ${ }^{4}$.

No cálculo do NPU, foi utilizada a seguinte fórmula:

$$
N P U=\frac{B-(B-B K)}{I} \times 100 \text { em que: }
$$

$B=$ nitrogênio corporal dos animais em dieta-teste; $B K=$ nitrogênio corporal dos animais em dieta aprotéica; e I = nitrogênio ingerido pelo grupo-teste.

A determinação do escore químico corrigido pela digestibilidade (PDCAAS) foi realizada nas farinhas de soja. Os valores de PDCAAS têm sido considerados um parâmetro recomendado pela Food and Agriculture Organization $^{8}$ para avaliar a qualidade da proteína em humanos ${ }^{9}$. Para o cálculo do PDCAAS, procedeu-se da seguinte forma: determinou-se o teor de nitrogênio; calculou-se o conteúdo protéico ( $\mathrm{N} \times 6,25)$; determinou-se o perfil de aminoácidos; determinou-se o escore de aminoácidos, como se segue (a proteína de referência utilizada foi o 
requerimento de aminoácidos para crianças de 2 a 5 anos conforme Food and Agriculture Organization ${ }^{10}$ :

$$
\begin{gathered}
\text { Escore de } \\
\text { aminoácido }
\end{gathered}=\frac{\begin{array}{l}
\text { mg do aminoácido essencial por g da } \\
\text { proteína-teste }
\end{array}}{\begin{array}{l}
\text { mg do aminoácido essencial por g da } \\
\text { proteína de referência }
\end{array}}
$$

Determinou-se a digestibilidade por ensaio biológico, conforme descrito anteriormente. Calculou-se o PDCAAS multiplicando-se o escore mais baixo de aminoácido essencial pela digestibilidade da proteína. Convencionou-se que a proteína cujo PDCAAS for igual ou superior a 1,0 é considerada de boa qualidade ${ }^{11}$.

Para se obter o perfil aminoacídico, as farinhas de soja foram submetidas à hidrólise ácida com $\mathrm{HCl} 6 \mathrm{Na} 110^{\circ} \mathrm{C}$ por 22 horas para determinação dos aminoácidos com exceção do triptofano e dos aminoácidos sulfurados, segundo metodologia descrita por Association of Official Analytical Chemists $^{12}$. Para recuperação dos aminoácidos sulfurados (metionina e cisteína), as amostras foram oxidadas com ácido perfórmico e depois hidrolisadas com $\mathrm{HCl} 6 \mathrm{~N}$. Posteriormente, as amostras hidrolisadas foram filtradas e injetadas em aparelho previamente calibrado com padrão externo. A determinação foi feita por cromatografia líquida de alto desempenho (HPLC). O princípio da detecção dos aminoácidos foi por derivatização dos aminoácidos com ninidrina formando um complexo colorido que foi quantificado espectrofotometricamente a 440nm (leitura da prolina) e 580nm (para leitura dos demais aminoácidos). O aparelho utilizado foi o Amino Acid Analyzer, modelo Hitachi L-8500 A, exclusivo para análises de aminoácidos.

Procedeu-se à análise estatística (ANOVA), para determinação do valor de " $F$ ". Para " $F$ " significativo, utilizou-se o teste de Tukey, a 5\% de probabilidade, para comparação entre as médias. A dispersão da média foi expressa nas tabelas de resultados como desvio-padrão da média.

\section{RESULTADOS E DISCUSSÃO}

É apresentado o resumo da composição química centesimal das farinhas de soja integrais utilizadas neste trabalho (Tabela 2). Pode ser observado que o teor de proteína variou de $38 \%$ a $42 \%$, lipídios de $21 \%$ a 23\%, umidade de 10\% a $12 \%$, cinzas de $6 \%$ a $7 \%$ e carboidratos de $17 \%$ a $20 \%$.

Os valores mostrados na Tabela 2 caracterizam uma farinha de soja integral e estão de acordo com os valores médios encontrados por Lima et al. ${ }^{13}$ para farinha de soja com teor de proteína menor ou igual a $45 \%$.

A qualidade protéica das farinhas foi determinada por ensaios biológicos com ratos, por meio de NPR, NPU, PER operacional e digestibilidade verdadeira.

Tabela 2. Composição química centesimal das farinhas de soja integrais* (g/100g).

\begin{tabular}{lccccc}
\hline Amostras & Umidade & Lipídios & Cinzas & Proteínas & Carboidratos \\
\hline FS1 & $11,22 \pm 1,03$ & $21,10 \pm 0,05$ & $6,45 \pm 0,19$ & $42,44 \pm 0,27$ & 18,77 \\
FS2 & $11,73 \pm 0,66$ & $22,61 \pm 0,68$ & $6,72 \pm 0,12$ & $38,32 \pm 0,66$ & 20,62 \\
FS3 & $10,54 \pm 1,15$ & $22,86 \pm 0,11$ & $7,05 \pm 0,02$ & $41,70 \pm 0,19$ & 17,85 \\
FS4 & $12,81 \pm 1,87$ & $23,74 \pm 0,05$ & $6,54 \pm 0,34$ & $39,55 \pm 1,14$ & 17,36 \\
\hline
\end{tabular}

*Valores são média \pm desvio-padrão.

FS1 - Farinha de soja integral sem LOX, sem KTI; FS2 - Farinha de soja integral sem LOX, com KTI; FS3 - Farinha de soja integral com LOX, sem KTI; FS4 - Farinha de soja integral com LOX, com KTI. 
As realizações de bioensaios são importantes porque mostram essencialmente a medida de aminoácidos limitantes utilizáveis pelo animal, ou seja, a biodisponibilidade dos aminoácidos das proteínas dos alimentos ${ }^{14}$.

Nos valores encontrados para NPR relativo à caseína, que variaram de $49 \%$ a $56 \%$ para as dietas à base de farinha de soja, observa-se que houve diferença estatisticamente significativa entre as médias dos valores de NPR da dieta com caseína das demais dietas e não houve diferença significativa entre os valores de NPR das dietas à base de farinha de soja. Isto demonstra que a qualidade da proteína da farinha de soja é inferior à caseína para promover crescimento e manutenção de peso de ratos (Tabela 3).

Os valores de NPR para as farinhas integrais de soja encontrados neste trabalho (Tabela 3) foram próximos aos valores encontrados por Miura et al. ${ }^{1}$ para farinha de soja desengordurada com baixa atividade de inibição, que foi em média 2,50 .

Observa-se que houve diferença significativa entre os valores de PER operacional da dieta com caseína das demais dietas e não houve diferença significativa entre os valores de PER operacional das dietas à base de farinha de soja (Tabela 3). Este fato demonstra que a qualidade da proteína da farinha de soja é inferior à caseína para promover crescimento dos animais, pois PER estima quanto da proteína ingerida é usada para promover crescimento do animal. Observa-se, também, que os valores de PER relativo para as dietas, tendo como fonte de proteína farinha de soja, variaram de $30,85 \%$ a $39,63 \%$, sendo que o valor de PER para a dieta a base de caseína foi de 3,76\%. Estes valores são inferiores aos encontrados por Rackis et al. ${ }^{15}$, que foi de $47,28 \%$ para dieta à base de farinha de soja desengordurada crua em experimentos com ratos. No presente trabalho foi utilizada farinha de soja integral, prejudicando a composição.

Pode ser observado que houve diferença significativa entre os valores de NPU da dieta de caseína das demais dietas e que não houve diferença significativa entre os valores de NPU das dietas à base de farinha de soja (Tabela 3). Este resultado demonstra que a qualidade da proteína das farinhas de soja é inferior à caseína para promover síntese protéica, pois NPU mede o quanto da proteína ingerida fica retida no organismo. A proteína da soja apresenta deficiência em alguns aminoácidos essenciais, resultando em eficiência inferior para síntese protéica quando comparado com a caseína, que é uma proteína com todos os aminoácidos essenciais em quantidades adequadas.

Observa-se também que os valores de NPU relativo para as dietas das farinhas de soja variaram de $44,28 \%$ a $53,93 \%$ e o NPU para a dieta de caseína foi de 70,57\% (Tabela 3). Estes valores são superiores ao valor encontrado por MORALES de Leon et al. ${ }^{16}$ para grãos de soja descascados e

Tabela 3. Valores de NPR, PER operacional e NPU das dietas de caseína e das farinhas de soja determinados em experimentos com ratos.

\begin{tabular}{lcccccc}
\hline & NPR* & RNPR $(\%)^{* *}$ & PER* & RPER $(\%)^{* *}$ & NPU* & RNPU (\%)** \\
\hline Caseína & $4,44 \pm 0.19 \mathrm{~A}$ & 100,00 & $3,76 \pm 0.21 \mathrm{~A}$ & 100,00 & $70,57 \pm 3,53 \mathrm{~A}$ & 100,00 \\
D1 & $2,34 \pm 0.24 \mathrm{~B}$ & 52,70 & $1,25 \pm 0.27 \mathrm{~B}$ & 33,24 & $38,06 \pm 9,05 \mathrm{~B}$ & 53,93 \\
D2 & $2,27 \pm 0.23 \mathrm{~B}$ & 51,13 & $1,16 \pm 0.32 \mathrm{~B}$ & 30,85 & $34,73 \pm 2,30 \mathrm{~B}$ & 49,21 \\
D3 & $2,52 \pm 0.27 \mathrm{~B}$ & 56,76 & $1,49 \pm 0.35 \mathrm{~B}$ & 39,63 & $36,52 \pm 5,74 \mathrm{~B}$ & 51,75 \\
D4 & $2,21 \pm 0.45 \mathrm{~B}$ & 49,77 & $1,33 \pm 0.45 \mathrm{~B}$ & 35,37 & $31,25 \pm 6,14 \mathrm{~B}$ & 44,28 \\
\hline
\end{tabular}

(*) As médias seguidas da mesma letra não diferem estatisticamente entre si, pelo teste de Tukey $(p<0,05)$; (**) RNPR $=$ NPR relativo;

${ }^{(* *)}$ RPER = PER relativo; ${ }^{(*)}$ RNPU = NPU relativo; D1 = dieta de farinha de soja integral sem LOX, sem KTI; D2 = dieta de farinha de soja integral sem LOX, com KTI; D3 = dieta de farinha de soja integral com LOX, sem KTI; D4 = dieta de farinha de soja integral com LOX, com KTI. 
crus que foi de 36,7\%. Também foram superiores ao valor de NPU relativo encontrado por Gutierrez et al. ${ }^{17}$ para dieta que contém mistura de sorgo e soja moída na proporção de 70:30, que foi de $34,22 \%$.

Observou-se que os resultados obtidos para PER operacional, NPR e NPU, não foram estatisticamente diferentes entre as farinhas derivadas de linhagens com presença e ausência de KTI. Isso indica que a ausência de KTI não alterou a qualidade protéica da farinha de soja.

A medida da digestibilidade indica o quanto das proteínas são hidrolisadas pelas enzimas digestivas e absorvidas pelo organismo, constituindo o primeiro fator que afeta a eficiência da utilização protéica da dieta (Tabela 4). Quando certas ligações peptídicas não são hidrolisadas no processo digestivo, parte da proteína é excretada nas fezes ou metabolizada pelos microorganismos do intestino grosso ${ }^{18}$.

A digestibilidade da dieta de caseína foi superior $(97,96 \%)$ e estatisticamente diferente, em nível de $5 \%$ de probabilidade, das demais dietas, cujos valores variaram de $88,16 \%$ a 93,40\% para digestibilidade relativa (Tabela 4). Observa-se também que houve diferença estatística entre as dietas com farinha de soja. As dietas que utilizam farinhas de soja derivadas de linhagens com ausência de KTI (D1 e D3) deram valores de digestibilidade superiores $(92,48 \%$ e 93,40\%), com diferença estatisticamente significativa em relação às dietas à base de farinhas de soja derivadas de linhagem contendo $\mathrm{KTI}$, cujos valores foram de $88,16 \%$ (D4) e 89,81\% (D2). Estes resultados mostram que a eliminação genética do inibidor de tripsina "Kunitz" dos grãos de soja promove melhoria significativa na digestibilidade da proteína de soja. Isto pode ser explicado com base na observação que KTI representa cerca de $80,0 \%$ dos inibidores de tripsina dos grãos de soja.

Os resultados apresentados na Tabela 4 indicam que a digestibilidade relativa das farinhas de soja com KTI (89,81\% e 88,16\%) está próxima dos valores encontrados por Rackis et al. ${ }^{15}$ para farinha de soja desengordurada tostada (89,52\%) e as digestibilidades relativas das farinhas de soja sem KTI $(92,48 \%$ e 93,40\%) foram superiores. Também os valores de digestibilidade das farinhas de soja sem KTI foram superiores aos valores encontrados por Friedman \& Gumbmann ${ }^{19}$, que foram de $84,19 \%$ para farinha de soja integral crua e de $88,06 \%$ para farinha de soja aquecida.

Tabela 4. Valores de digestibilidade das dietas de caseína e das farinhas de soja determinados em experimentos com ratos.

\begin{tabular}{lcc}
\hline Dieta & Digestibilidade* $^{*}$ & R Digestibilidade** $(\%)$ \\
\hline Caseína & $97,96 \pm 0,41$ A & 100,00 \\
D1 & $90,59 \pm 1,93$ B & 92,48 \\
D2 & $87,98 \pm 0,56$ C & 89,81 \\
D3 & $91,50 \pm 1,30$ B & 93,40 \\
D4 & $86,36 \pm 0,89$ C & 88,16 \\
\hline
\end{tabular}

${ }^{(*)}$ As médias, dentro da mesma coluna, seguidas pelas mesmas letras não diferem estatisticamente entre si pelo teste de Tukey $(p<0,05)$; ${ }^{(* *)} \mathrm{R}=$ digestibilidade relativa em \%; D1 = dieta de farinha de soja integral sem LOX, sem KTI; D2 = dieta de farinha de soja integral sem LOX, com KTI; D3 = dieta de farinha de soja integral com LOX, sem KTI; D4 = dieta de farinha de soja integral com LOX, com KTI.

Os resultados encontrados no presente trabalho demonstram que as dietas que contêm farinha de soja como única fonte de proteínas derivadas de linhagens com ausência de KTI apresentam melhor digestibilidade do que dietas que contêm farinha de soja de linhagens com KTI. Herkelman et al. ${ }^{20}$ estudaram o efeito de cultivar (com teor normal $\mathrm{x}$ baixo teor de KTI) e do tratamento térmico sobre a digestibilidade aparente da proteína da soja em suínos. Estes autores observaram que animais com dietas que contêm soja convencional apresentaram desempenho inferior aos de animais que receberam dietas que contém soja com baixo teor de KTI, porém um adequado tratamento térmico é requerido para melhorar o valor nutricional de ambos os tipos de soja.

Para o cálculo do PDCAAS foi realizada, primeiramente, a determinação da composição aminoacídica das farinhas de soja integrais. 
Observou-se que os teores de aminoácidos das quatro farinhas integrais estudadas neste trabalho praticamente não diferem entre si. Isso demonstra que a retirada do KTI e LOX parece não ter alterado a composição aminoacídica dessa soja (dados não mostrados).

Os valores de PDCAAS para FS1 (75,19\%), FS2 (80,94\%), FS3 (79,60\%) e FS4 $(77,72 \%)$ foram inferiores aos encontrados para digestibilidade verdadeira, que foram para FS1 90,59\%, FS2 87,98\%, FS3 91,50\% e FS4 86,36\% (Tabela 5). Pelos valores da digestibilidade verdadeira, foi possível detectar diferença entre farinhas derivadas de linhagens sem KTI e as de linhagens com KTI. Conclui-se, portanto, que os valores de digestibilidade verdadeira foram mais eficientes para detectar o efeito da eliminação genética do KTI na farinha de soja do que os valores de PDCAAS. Os valores de PDCAAS encontrados neste trabalho foram próximos aos valores encontrados por Sarwar ${ }^{9}$ para farelo de soja crua desengordurado (80\%).

Os resultados demonstram, ainda, que o aminoácido limitante para as farinhas de soja analisadas foi lisina e não metionina + cisteína, como seria esperado (Tabela 5). Blanco \& Bressani ${ }^{21}$ citam que proteínas de leguminosas têm como fator limitante o teor de aminoácidos sulfurados. O fato de as farinhas de soja do presente trabalho apresentarem como fator limitante o aminoácido lisina em vez de metionina + cisteína pode ser explicado por alterações que ocorreram na composição protéica desta linhagem pelo melhoramento genético.

\section{O N CLUSÃ O}

A eliminação genética do KTI promove melhora acentuada na digestibilidade da proteína de soja, comprovando que esse inibidor é o principal fator antinutricional responsável pela diminuição da digestibilidade da proteína de soja e, conseqüentemente, pela menor absorção desta pelo organismo animal. Os valores de digestibilidade das farinhas de soja com ausência de KTI foram bem próximos ao da caseína.

Com relação à avaliação da qualidade protéica das farinhas de soja, observou-se que os índices PER operacional, NPR e NPU tiveram desempenho inferior ao da proteína-padrão

Tabela 5. Valores de PDCAAS das farinhas de soja integrais.

\begin{tabular}{|c|c|c|c|c|c|c|c|c|c|c|c|c|c|}
\hline \multirow[t]{2}{*}{$\begin{array}{c}\text { I } \\
\text { AA essencial }\end{array}$} & \multicolumn{4}{|c|}{$\begin{array}{c}\| \\
\text { mg/g proteína }\end{array}$} & \multirow{2}{*}{$\begin{array}{c}\text { III } \\
\text { Padrão } \\
\text { FAOMHO }\end{array}$} & \multicolumn{4}{|c|}{$\begin{array}{c}\text { IV } \\
\text { Escore AA }\end{array}$} & \multicolumn{4}{|c|}{$\begin{array}{c}V \\
\text { PDCAAS }^{2}\end{array}$} \\
\hline & FS1 & $\mathrm{FS} 2$ & FS3 & FS4 & & FS1 & FS2 & FS3 & FS4 & FS1 & FS2 & FS3 & FS4 \\
\hline Fenil + Tir. & 70,81 & 77,87 & 73,90 & 75,98 & 63 & 1,12 & 1,24 & 1,17 & 1,21 & & & & \\
\hline Histidina & 23,74 & 25,73 & 24,95 & 25,44 & 19 & 1,25 & 1,35 & 1,31 & 1,34 & & & & \\
\hline Isoleucina & 37,97 & 42,64 & 40,58 & 41,99 & 28 & 1,36 & 1,52 & 1,45 & 1,50 & & & & \\
\hline Leucina & 74,01 & 81,92 & 78,17 & 81,53 & 66 & 1,12 & 1,24 & 1,18 & 1,23 & & & & \\
\hline Lisina & 48,42 & 53,64 & 50,47 & 52,20 & 58 & 0,83 & 0,92 & 0,87 & 0,90 & $0,75^{3}$ & $0,81^{3}$ & $0,80^{3}$ & $0,78^{3}$ \\
\hline Met + Cist. & 26,31 & 29,50 & 28,24 & 28,25 & 25 & 1,05 & 1,18 & 1,13 & 1,13 & & & & \\
\hline Treonina & 36,13 & 39,38 & 38,04 & 39,00 & 34 & 1,06 & 1,16 & 1,12 & 1,15 & & & & \\
\hline Triptofano & nd & nd & nd & nd & 11 & nd & nd & nd & nd & & & & \\
\hline Valina & 38,20 & 45,05 & 43,00 & 44,97 & 35 & 1,09 & 1,29 & 1,23 & 1,28 & & & & \\
\hline
\end{tabular}

(1) Escore de AA = coluna II / coluna III; (2) PDCAAS = 10. aminoácido limitante (coluna IV) $x$ digestibilidade verdadeira do experimento com ratos; (3) PDCAAS: FS1 = 0,75 ou 75\%; FS2 = 0,81 ou 81\%; FS3 = 0,80 ou 80\% e FS4 = 0,78 ou 78\%; Digestibilidade verdadeira: FS1 = 90,59 ou 0,9059; $\mathrm{FS} 2=87,98$ ou 0,$8798 ; \mathrm{FS} 3=91,50$ ou 0,915 e FS4 = 86,36 ou 0,8636. 
caseína. Estes resultados já eram esperados, tendo em vista que a proteína de soja, reconhecidamente, é deficiente em alguns aminoácidos essenciais, o que limita a sua utilização para síntese protéica.

Os aminoácidos sulfurados são considerados limitantes na soja, porém constatou-se, por meio da análise da composição de aminoácidos nessas farinhas, que o limitante nessa variedade em estudo é o aminoácido lisina.

A ausência de KTI, embora tenha promovido melhoria na digestibilidade da proteína, não afetou seu desempenho para promover retenção de $\mathrm{N}$ e crescimento de ratos recém-desmamados.

Os resultados do PDCAAS para as farinhas de soja estão de acordo com os resultados encontrados por outros autores, porém, esse índice não foi eficiente para detectar a melhoria da retirada genética do KTI da soja.

\section{REFERÊ NCIAS}

1. Miura EMY, Binotti MAR, Camargo DS, Mizubuti IY, Ida El. Avaliação biológica de soja com baixas atividades de inibidores de tripsina e ausência do inibidor Kunitz. Arch Latinoam Nutr 2001; 51(2):1-8.

2. Sant'ana LFR, Costa NMB, Oliveira MGA, Gomes MRA. Valor nutritivo e fatores antinutricionais de multimisturas utilizadas como alternativa alimentar. Braz J Food Technol 2000; 3:129-35.

3. Vasconcelos IM, Maia AAB, Siebra EA, Oliveira JTA, Carvalho AFFU, Melo VMM, et al. Nutritional study of two Brazilian soybean (Glycine max) cultivars differing in the contents of antinutritional and toxic proteins. J Nutr Biochem 2001; 12:55-62.

4. Association of Official Analytical Chemists. Official methods of analysis of the Association of Official Analytical Chemists. 14th ed. Washington, DC; 1984. $1141 \mathrm{p}$.

5. Reeves PG, Nielsen FH, Fahey GC. AIN-93 purified diets for laboratory rodents: final report of the american institute of nutrition ad hoc writing committee on the reformulation of the AIN-76A rodent diet. J Nutr 1993; 123(11):1939-51.

6. Bender $A E$, Doell BH. Note on the determination of net protein utilization by carcass analysis. $\mathrm{Br} J$ Nutr 1957; 11:138-43.

7. Miller DS, Bender AE. The determination of the net utilization of proteins by a shortened method. Br J Nutr 1955; 9:382-8.

8. Food and Agriculture Organization. Protein quality evaluation. Rome; 1991. 66p. (FAO Food and Nutrition Paper, 51).

9. Sarwar G. The protein digestibility-corrected amino acid score method overestimates quality of proteins containing antinutritional factors and of poorly digestible proteins supplemented with limiting amino acids in rats. J Nutr 1997; 127:758-64.

10. Food and Agriculture Organization. Energy and protein requirements. Geneva; 1985. 724p.

11. Henley EC, Kuster JM. Protein quality evaluation by protein digestibility corrected amino acid scoring. Food Technol 1994; 48:74-7.

12. Association of Official Analytical Chemists. Official methods of analysis of the Association of Official Analytical Chemists. 15th ed. Washington, DC; 1990. p.1105-6.

13. Lima GJMM. Importância da qualidade nutricional da soja e de seus subprodutos no mercado de rações: situação atual e perspectivas futuras. In: Congresso Brasileiro de Soja; 1999; Londrina. Londrina: Embrapa; 1999. 533p.

14. McLaugaulan JM, Keith OM. Biossays for protein quality. In: Frieedman M, editor. Protein nutritional quality of foods and feeds. New York: Marcel Dekker; 1975. p.79-85.

15. Rackis JJ, Gunbmann MR, Liener IE. The USDA trypsin inhibitor study. I. background, objectives and procedural details. Qual Plant Food Hum Nutr 1985; 35:213-42.

16. Morales de León JC, Rodrigues HB, Zardain MI. Cooking procedures fordirect consumption of whole soybeans. Arch Latinoam Nutr 1985; 35(2):326-36. 
17. Gutierrez RR, Romano MA, Gomez MH. Evaluación nutricional y de estabilidad durante el almacenamiento de mezclas extruidas com sorgo. Arch Latinoam Nutr 1987; 37(3):503-14.

18. Stipanuk MH. Biochemical and physiological aspects of human nutrition. Philadelphia: Saunders Company; 2000.

19. Friedman M, Gumbmann MR. Nutritional improvement of soy flour through inactivation of trypsin inhibitors by sodium sulfite. J Food Sci 1986; 51:1239-41.
20. Herkelman KL, Cromwell GL, Pfeiffer TW, Knabe DA. Apparent digestibility of amino acids in raw and heated conventional and low trypsin inhibitor soybeans for pigs. J Anim Sci 1992; 70(3): 818-26.

21. Blanco A, Bressani R. Biodisponibilidad de aminoácidos in el frijol (Plhaseolus vulgaris). Arch Latinoam Nutr 1991; 41(1):38-51.

Recebido para publicação em 26 de novembro de 2002 e aceito em 17 de junho de 2003. 